\title{
Carrot and Stick? The role of financial market intermediaries in Corporate Social Performance.
}

Author Details (please list these in the order they should appear in the published article)

Author 1 Name: Rieneke Slager

Department: ICCSR, Nottingham University Business School

University/Institution: The University of Nottingham

Town/City: Nottingham

State (US only):

Country: UK

Author 2 Name: Wendy Chapple

Department: ICCSR, Nottingham University Business School

University/Institution: The University of Nottingham

Town/City: Nottingham

State (US only):

Country: UK

Author 3 Name:

Department:

University/Institution:

Town/City:

State (US only):

Country:

\section{Author 4 Name:}

Department:

University/Institution:

Town/City:

State (US only):

Country:

NOTE: affiliations should appear as the following: Department (if applicable); Institution; City; State (US only); Country. 
Corresponding author: Rieneke Slager

Corresponding Author's Email: Rieneke.Slager@nottingham.ac.uk

$\square$ Please check this box if you do not wish your email address to be published

\section{Acknowledgments (if applicable):}

This research was funded by the ESRC Case studentship scheme. We would like to express our gratitude to the FTSE-RI team for their support throughout this research project.

\section{Biographical Details (if applicable):}

[Author 1 bio]

[Author 2 bio]

[Author 3 bio]

[Author 4 bio]

\section{Structured Abstract:}

In this paper we examine the role of intermediaries in financial markets in fostering corporate sustainability. Responsible Investment (RI) indices have been primarily identified as intermediaries that provide information regarding Corporate Social Performance (CSP) for investors and other stakeholders (Doh et al. 2010, Consolandi et al. 2009). We argue that the role of these intermediaries is not confined solely to information provision, but they may also incentivize high levels of CSP through mechanisms such as exclusion threats, signalling, and engagement. We rely on unique access to the archives of the FTSE4Good Index to examine the effects of these mechanisms on CSP. The study shows that companies facing exclusion threats and signalling are more likely to comply with the intermediary's criteria, and medium levels of engagement leads to higher levels of CSP. We contribute to the study of sustainability in financial markets by explicating the mechanisms that intermediaries and other financial actors could employ in order to foster greater corporate sustainability. 
Keywords:

Engagement, RI indices, CSP, intermediaries 
Article Classification:

For internal production use only

\section{Running Heads:}




\section{Carrot and Stick? The role of financial market intermediaries in Corporate Social Performance}

Intermediaries play an increasingly important role for equity market participants interested in sustainability and business responsibility. Responsible Investment (RI), defined here as the integration of investors' financial objectives with an evaluation of corporate environmental, social and governance concerns, relies on intermediaries to measure the responsible behaviour of companies. One popular group of metrics are RI indices, which are essentially weighted listings of stocks that are typically constructed by filtering a broader universe of stocks according to a set of Corporate Social Performance (CSP) criteria. RI indices, such as the Dow Jones Sustainability Index, the Domini Social Index and the FTSE4Good Index, are used by investors for the benchmarking of RI funds and the creation of related investment products. They may also serve to signal CSP reputation to investors and other stakeholders (Doh et al, 2010), as these indices allow them to make a judgment of the extrafinancial 'quality' of corporate stocks. Most of the studies regarding RI indices have focused on the effect of inclusion or exclusion from indices on corporate share prices (e.g. see Consolandi et al, 2009; Collison et al, 2008; Capelle-Blancard \& Couderc, 2009; Wai, 2011: Robinson,

Kleffner \& Bertels, 2011; Curran \& Moran, 2007). However the question remains whether these intermediaries may also have an effect on CSP, and if so, what the key mechanisms are to bring about these effects?

We argue that the role of intermediaries such as RI indices is not limited solely to information provision, but that they may also contribute to higher levels of CSP 
in a context where standards for CSP continue to evolve (Bertels \& Peloza, 2008). We identify three mechanisms that may move companies towards high CSP over time: threatening exclusion from the index when CSP scores do not meet the benchmark, signalling CSP reputation through publication of index inclusion, and constructing effective dialogue on CSP through engagement. We show that these mechanisms can be effectively used to influence the CSP of large numbers of companies over time. We study the FTSE4Good Index, launched in 2001 by the UKbased index provider FTSE Group to evaluate the environmental and social performance of companies listed on the major stock exchanges around the world. Through unique access to the archives and data related to the FTSE4Good Index, we study the introduction of a new set of CSP criteria on anti-bribery and corruption practices. We highlight how exclusion threats, signalling and engagement influence levels of CSP. In so doing, we contribute to reputation and legitimacy studies by showing that the role of intermediaries may involve more than pure information provision to investors and stakeholders.

We also

contribute to the theoretical development of studies on shareholder engagement and activism, by explicating the mechanisms that influence CSP. Very little is known about the effectiveness of engagement, especially on a larger scale (Gond \& Piani, 2013). We provide what we believe is one of the first large-N studies of the effect of engagement on corporate behaviour. Based on our dataset we show that engagement can be effective in influencing levels of CSP even when applied to large numbers of companies. Our results show how engagement interacts with corporate reputation and legitimacy in fostering compliance with intermediaries CSP criteria and may lead to higher levels of CSP.

The paper is structured as follows: first we review the role of intermediaries in conferring corporate reputation and legitimacy that has been previously identified in the literature. Next, we build our hypotheses related to the three mechanisms for influencing CSP, and describe our 
methods for testing these in the case of the FTSE4Good Index. We continue to present the results and conclude with a discussion of the implications of our findings for the study of intermediaries, CSP and engagement.

\section{Intermediaries as information providers}

Intermediaries play an important role in markets that are characterised by information asymmetries. Studies on a wide range of intermediaries such as certification bodies (Rao, 1994, 1998), media rankings (Rindova et al 2005), and financial analysts (Zuckerman, 2000; Benner \& Ranganathan, 2012), show that where there is a lack of concrete information about aspects of firm performance, or performance is difficult for the general public to observe, evaluation by intermediaries provides legitimacy and reputation signals that might in turn influence financial performance. Fombrum \& Shanley (1990) find evidence that CSP forms a subset of the signals that corporate reputation is based on, but due to information asymetries stakeholders are reliant on intermediaries to evaluate CSP. In a similar vein, Doh et al (2010) argue that aspects of CSP are difficult to observe by an organisation's stakeholders, and that RI indices act as 'institutional intermediaries' which 'by including (or excluding) firms from their indices...send clear and strong signals to investors about whether firms have met the credible Corporate Social Responsibility criteria established by these organisations' (Doh et al 2010: 1466).

Research into the main RI indices in the RI market, has focused mainly on the financial performance of these indices (Collison et al., 2008) or the effect of inclusion and exclusion from the indices on share price (Capelle \& Couderc, 2009; Wai, 2011; Robinson et al, 2011; Doh et al, 2010).These studies have not examined whether inclusion in RI indices can have effects on CSP. There is increasing evidence that the measurement by intermediaries is not neutral, but may act to incentivise improvements in what is being measured, 
especially when reputational stakes are high (Sauder, 2006; 2008; Sauder \& Espeland, 2009). Studies in the context of higher education show that obtaining a good evaluation by intermediaries in rankings and ratings becomes an important part of maintaining organisational reputation, and that many organisations will adjust their behaviour to obtain a favourable evaluation (Sauder 2006; 2008; Sauder \& Espeland, 2009). We argue that the signal for reputation and legitimacy provided by RI indices may similarly influence levels of CSP. Researching these effects will provide better understanding of the role of intermediaries in fostering sustainability, and responds to the call for research that examines CSP as the dependent variable (Waddock \& Graves, 1997).

A potential explanation for the lack of understanding about intermediaries' role in influencing CSP may derive from the fact that most studies focus on the informational role of intermediaries only. In essence, these studies take the outcome of the evaluation process undertaken by the intermediary as given, and study the effect of the outcome on share price. In doing so, important processes and mechanisms that might spur higher levels of CSP are missed. For example, our study shows that intermediaries engage with corporations to gather CSP information and provide advice about the evaluation criteria. This engagement tries to convince companies to aim for higher levels of CSP, just like shareholder engagement (Clark \& Hebb, 2004; Southwood, 2003) or shareholder dialogue (Logsdon \& van Buren, 2009) aims to do. Because shareholder engagement often takes place in private conversations between corporate management and the engaging party, it is difficult to measure its effects on a large scale. Based on the unique dataset we gathered for our study of the FTSE4Good Index, which includes correspondence between the two parties in engagement, we can show that engagement is an important mechanism that can be used by intermediaries to influence levels of CSP. In the next section we build our theoretical framework explicating the mechanisms that may influence CSP through intermediaries in RI markets. 


\section{Three mechanisms for influencing CSP}

Drawing from and extending previous literatures, we identify three mechanisms underlying RI indices that may influence levels of CSP: the threat of index exclusion (labelled exclusion threat), the signalling of CSP reputation through the publication of index inclusion (labelled signalling), and the establishment of an engagement dialogue regarding required CSP levels (labelled engagement). We discuss each in turn, but first distinguish between two key concepts in our framework: legitimacy and reputation.

In the literature on corporate reputation, the economic perspective emphasises individual firm attributes such as efficiency or financial performance, whilst the institutional perspective focuses on a firm's relative status amongst its peers (Doh et al, 2010; Rindova et al, 2005; Love \& Kraatz, 2009).

Legitimacy, a concept of central concern in institutional theory, can be seen as a precursor to reputation (Doh et al, 2010; Rindova et al, 2005:

Deephouse \& Carter, 2005). From this perspective legitimacy is derived from the adherence to commonly accepted standards and norms of corporate behaviour in an organisational field (Suchman, 1995; Scott, 2001; Deephouse \& Suchman, 2008). Corporate reputation may be derived from adherence to the same norms and standards that define legitimacy, but additionally is derived from relative performance against the firm's peers in that field (King \& Whetten, 2008; Deephouse \& Carter, 2005). Thus, the evaluation of adherence to commonly accepted norms and standards plays a central role in both conferring legitimacy and signalling reputation (Deephouse \& Suchman, 2008).

The conferring of legitimacy through index inclusion is the most widely acknowledged role of RI indices. For example, Consolandi et al (2009) argue that inclusion in RI indices confers legitimacy as it shows compliance with global CSP standards to investors and stakeholders of the company. RI indices can be used by investors for identifying target companies for engagement, especially with those 
companies that are not included (Oulton, 2006). Additionally, the indices have also become a tool for a wider group of actors within the CSP industry. NGOs use them as a tool to identify 'good' companies to partner with or 'bad' companies to campaign against, while consultants may identify excluded companies as profitable potential clients (Slager, Gond \& Moon, 2012).

The conferring of legitimacy is a powerful incentive to improve CSP for those companies who do not meet the mark set by the intermediary (Consolandi et al, 2009). Chatterji and Toffel (2010) find that firms will improve their performance in response to poor ratings from RI intermediaries, in order to mitigate the threat of stakeholder sanctions. Yet research suggests the threat of taking away this legitimacy, once conferred, may provide even stronger incentives for change. Doh et al (2010) find that the effect on share price is limited to those firms that are deleted from the Calvert Social Index, and attribute this to asymmetric information on poor CSP performance. They argue that because of this asymmetry, deletion will come as more of a surprise to investors than inclusion (Doh et al 2010:1479). In line with this, Scalet and Kelly (2009) find that most firms don't communicate about negative events that lead to an exclusion from ratings. The idea that bad news attracts more attention than good news may also underlie the fear of being excluded from RI indices reported by managers in a survey of the FTSE4Good Index (Collison et al., 2009).

Most RI indices change their criteria for good CSP over time, to take into account current developments and changing global standards relating to environmental, social and governance performance (Bertels \& Peloza, 2008). For example both the FTSE4Good Index and the DJSI have added assessment criteria for issues such as climate change and supply chain standards in the last decade (FTSE, 2011, RobecoSAM, 2013). This means companies that may have previously met the intermediaries' criteria for good CSP need to improve their CSP in order to ensure their continued conformance. This process of raising the bar for index inclusion entails a threat to those 
companies who in the past met the CSP criteria, but now face exclusion. Following the logic that exclusion has stronger effects than inclusion, we propose that companies which face this threat are more likely to work towards compliance with the intermediaries' CSP criteria in order to avoid the threat of exclusion:

Hypothesis 1: Those companies who are threatened by exclusion from RI indices are more likely to comply with the intermediary's general CSP criteria for index inclusion in subsequent years.

The inclusion of a firm in a RI index may act as the endorsement (Rhee \& Valdez, 2009) of that firm's CSP because the evaluation by RI intermediaries is perceived to be objective and in accordance with global standards (Doh et al, 2010). RI indices provide 'a normative benchmark for firms seeking to achieve a positive reputation for corporate social responsibility and [...] a guidepost for audiences concerned about the socially responsible practices of companies they invest in' (Doh et al, 2010: 1470). Although often ignored in studies on intermediaries, it is important to acknowledge the active role of firms themselves in signalling reputation through using intermediaries' endorsements (Deephouse and Suchman 2008). Although inclusion in the indices itself could be seen as signal of meeting norms, firms often enhance this signalling effect, by communicating inclusion in indices in corporate materials. For example, many firms use the logos of RI indices in their CSP disclosure as a certification of good CSP (Consolandi et al, 2009), and the legitimacy of these signals are thus co-constructed between firms and intermediaries (Durand \& McGuire, 2005). These firms use the assessment by RI intermediaries and resultant inclusion in RI indices as a 'stamp of approval' for CSP performance, and, in the absence of other global standardised assessment measures of CSP, this is often valorised as such by other parties, such as NGO's, the media, and consultants (Slager et al, 2012). 
Research on the use of third party assessments in the field of higher education shows that their ubiquitous nature in organisational communications increases their reputation effects (Sauder 2006; 2008). Nevertheless, not all companies will recognise and use index inclusion to signal good CSP performance. Given that companies may choose to use intermediary endorsements for reputation signalling purposes, we expect that companies that use RI indices to signal CSP reputation will ensure their continued conformance with the standards set by RI indices, as their failure to do so will lead to reputational damage. In addition, we expect that these companies have higher levels of CSP in subsequent years:

Hypothesis 2a: Those companies that signal CSP reputation to their stakeholders through intermediary endorsements are more likely to comply with the intermediary's general CSP criteria for index inclusion in subsequent years.

Hypothesis 2b: Those companies that signal CSP reputation to their stakeholders through intermediary endorsements are more likely to have higher levels of CSP in subsequent years.

Shareholder engagement is becoming increasingly popular as a RI strategy in Europe (Clark \& Hebb, 2004; Southwood, 2003) and the US, where it has been termed 'Dialogue' to distinguish it from more aggressive shareholder activism (Logsdon \& van Buren, 2009). Due to the private nature of shareholder engagement, which often takes place behind the closed doors of the company boardroom, little is known about the organisational context and process of engagement (Gond \& Piani, 2013). From existing qualitative, small N studies we can distil four factors that are common in shareholder engagement processes, and which, as we'll show below, also feature in engagement undertaken by intermediaries such as FTSE in relation to their FTSE4Good Index. First, in their dialogue with corporate management shareholders often frame their concerns 
regarding poor CSP in terms of reputational risk and potential impact on long term financial performance (Gond \& Piani, 2013). Second, there is an emphasis on building trust in the dialogue with corporate management, with antagonistic tactics generally being eschewed (Vandekerckhove, Leys \& Van Braeckel, 2007; McLaren, 2004). Third, the goals of the dialogue may simply be information exchange on the issue of concern or include more extensive influencing of corporate policies or reporting that are drawn up in response (Gond \& Piani, 2013; Gifford, 2010). Lastly, dialogues are often drawn out over extensive periods of time, and the threat of more aggressive tactics such as filing shareholder resolutions or selling of shares is often only used implicitly (Gifford, 2010; Logsdon \& van Buren, 2009). Sullivan and MacKenzie (2008) argue that objectives of this private dialogue with shareholders may be to raise the profile of CSP with corporate management, legitimise debate about contentious issues and encourage management to meet certain CSP standards. Logsdon and van Buren (2009) highlight that, compared to shareholder activism, effective engagement requires different skills and tactics, including patience, effective dialogue and trust (Logsdon and van Buren 2009).

Whilst shareholders may have more salience than other stakeholder groups, engagement tactics are not the sole domain of shareholders. Similar tactics may be employed by RI intermediaries. Slager et al (2012) show that engagement efforts are central to the construction of the FTSE4Good Index, both in terms of convening stakeholders to set CSP criteria, and through direct dialogue with companies when CSP criteria are ratcheted up. Index engagement shares some of the main characteristics of shareholder engagement described above: it consists of a long term dialogue, framed around information exchange on CSP performance and influencing corporate policies or reporting on CSP issues. Similarly, index engagement requires skills, time and resources that can be accumulated over time (Slager et al, 2012). It focuses on those 
companies under threat of exclusion from the Index, who are invited to engage in dialogue about their CSP and the Index criteria. This aims to raise levels of CSP over time, and enables them to remain included in the FTSE4Good Index as new criteria on specific issues such as countering bribery are introduced. Engagement is voluntary, and companies may choose not to respond to the intermediary. We argue that companies who do respond and participate in engagement are more likely to comply with the new criteria and to have higher performance in the respective area of CSP following the guidance given by the intermediary during the engagement process. Just like with shareholder engagement, effective index engagement requires time and active participation from companies. The more both parties actively engage in dialogue, the more likely it is this will affect levels of CSP. Thus, engagement presents a third mechanism that may be employed to influence levels of CSP on specific issues of engagement:

Hypothesis 3: Those companies that take part in higher levels of engagement with the intermediary are more likely to have higher levels of CSP in subsequent years.

\section{Methods}

For our study we collected a unique dataset relating to the FTSE4Good Index, consisting of private correspondence, CSP data and corporate data. Companies that meet the FTSE4Good Index CSP criteria are automatically included in the FTSE4Good Index (i.e. they do not self-select to be included). During the period analysed information on CSP was gathered and scored independently by social research agency EIRIS, which collects and evaluates information from company reports, webpages and information directly provided by companies. Twice a year the 
FTSE4Good Policy Committee convenes to review the Index CSP criteria and include or exclude companies. The FTSE4Good Index has the dual objective to serve investors interested in RI, and to incentivise companies to improve their CSP through raising the bar for Index inclusion (FTSE, 2010; Slager et al, 2012; Mackenzie, Rees, \& Rodionova, 2013). Additional inclusion criteria have been introduced throughout the years since the Index was launched, on topics as diverse as climate change, supply chain labour standards and anti-bribery practices.

In this paper we study the effects of the exclusion threats, signalling, and engagement specifically related to the FTSE4Good Countering Bribery (CB) criteria, first announced in July 2006. This new category of CSP criteria require 'high risk' companies operating in corrupt environments to have in place policies and management systems to counter bribery and corruption in their operations, and to publicly report on their policies and management systems. The risk categorisation is based on industry sectors, countries of operation and involvement in government contracts. Appendix A lists the high risk categorisation and criteria indicators in full.

The FTSE4Good Index is managed on a day-to-day basis by the FTSE RI team. During the introduction of the new Countering Bribery criteria, the FTSE RI team firstly provided information regarding the criteria to companies; secondly it provided warnings to those companies which were in the Index but were not meeting the new criteria; and subsequently it tried to engage in dialogue with these companies. In the engagement process companies had the chance to provide evidence to show they are working towards meeting the criteria, a process which may take several months to years. The FTSE4Good Policy Committee ultimately decides whether a company should be excluded from the Index after this period of engagement, based on an evaluation of information provided by EIRIS and the FTSE RI team. 
For this study's sample, we selected all listed European companies that were categorised by EIRIS as operating in an environment with high risk for encountering bribery. Fifty-seven percent of companies in the sample were included in the FTSE4Good Index in the observation period, hence roughly forty percent were not included in the Index. ${ }^{1}$ The resulting panel is unbalanced due to mergers, acquisitions etc., and is presented as a pooled panel. The total sample includes 254 companies and 813 observations. The observation period began in 2007 and ended in 2010 .

This period was chosen because we expected the full effects of the mechanisms identified (exclusion threat, signalling, and engagement) to be observable within this period. Table 1 describes the variables used in the study and their data sources.

\section{Insert table 1 about here}

\section{Dependent variable}

Data regarding the new FTSE4Good Countering Bribery criteria started to be collected by EIRIS from 2006 onwards following a consultation led by FTSE to define methodology Data exists for most companies categorised as high risk from 2007. The data for 2007 is therefore taken as a baseline in the study. The data covers the EIRIS evaluation of the quality of anti-bribery policies, management systems and corporate reporting. These three elements are rated by text grades: no evidence, limited, intermediate, good and advanced. In line with previous use of the EIRIS database by Brammer and Millington (2008), the text gradings are converted into numerical scores. Because the number of companies rated

\footnotetext{
${ }^{1}$ The companies that are not in the Index do not meet either the technical criteria (free float, market cap); the other FTSE4Good inclusion criteria; or the exclusion criteria (e.g. companies involved in production of weapon systems). All companies in the sample are classified by EIRIS as operating in environment with high risk for corruption and bribery.
} 
good is low $(\mathrm{N}<10)$, the categories of good and advanced are merged into one, leading to numerical scores between $0-3$ on the each of the three elements. As the 'intermediate' grade was designed to reflect the FTSE4Good index inclusion threshold, this still provides enough information for the analysis.

The analysis employs two dependent variables: compliance with the overall FTSE4Good Index inclusion criteria and the quality of Countering Bribery practices in particular. The first dependent variable, compliance, is a binary variable that identifies companies that have the received the minimum score that is needed to remain in the FTSE4Good Index. Thus a 1 signifies the company complies with the Index criteria, and has the level of CSP that is required to remain in the index. Data on compliance for the observation period is taken from the FTSE4Good database. The compliance dependent variable is used to test hypothesis 1 and $2 \mathrm{a}$. Whilst the first dependent variable provides a binary indication of broad compliance with the Index criteria, we create a second dependent variable to test a fuller range of performance on a specific CSP issue. The second dependent variable, Countering Bribery practices, is the summed total score for the three Countering Bribery criteria elements, as given by EIRIS. A company with elaborate and high quality Countering Bribery practices receives a higher score than those companies which disclose little about their countering bribery practices or lack appropriate policies and management systems. Thus higher levels of the dependent variable reflect higher levels of CSP in this area. We include this second dependent variable in our analysis in particular to test the effects of engagement on the new Countering Bribery criteria that took place during the observation period (see below); it is thus used to test hypothesis $2 \mathrm{~b}$ and 3. Whilst subsuming CSP aspects into one aggregate score has been criticised as theoretically and empirically unsound (Griffin \& Mahon, 1997), here the aggregated score is less problematic because it measures only one aspect of CSP. 
The independent variables are created based on FTSE4Good archival data and corporate data. The FTSE4Good archival data collected includes a longitudinal database that is used to identify all companies eligible for Index inclusion based on their CSP scores. It also includes private correspondence between companies and the FTSE RI team, such as formal letters, emails and minutes of meetings. The correspondence is normally started by the FTSE RI team when a company is warned regarding not meeting the Countering Bribery criteria. The subsequent dialogue would include for example discussions about definitions of whistle blowing or facilitation payments; companies providing more information about anti-bribery managing systems; or questioning appropriate forms of corporate reporting. The dialogue is continued until the company meets the criteria or is deleted from the Index. The data collected from FTSE4Good and corporate sources was used to create three independent variables as proxies for the three mechanisms identified.

First, we create a binary measure of exclusion threat. Data regarding the compliance of European companies with the Countering Bribery criteria were extracted from the FTSE4Good archives. A company is coded 1, if it does not meet the Countering Bribery criteria, but continues to be included in the Index in that year. It is coded 0 otherwise. This binary measure corresponds to those companies facing the threat of exclusion from the Index due to not meeting the Countering Bribery criteria at that point in time. It serves as a precursor to the process of engagement (see below) which may serve to incentivize compliance with the Index criteria in subsequent years. To allow for this time effect exclusion threat is lagged by one year in the analysis. 
Second, we create the measure of signalling by examining CSP disclosure. If a company in the FTSE4Good Index advertises the fact that it is included in the Index, this can signal reputation for 'good CSP', and act as a reputation differentiator (Suchman \& Deephouse, 2008). FTSE does not advertise the complete list of Index constituents. Instead, companies may opt to undertake this signalling through promoting Index inclusion as a de facto certification of their CSP (Slager et al, 2012; Consolandi et al, 2009). To assess whether a company was using FTSE4Good as a signalling tool, stand-alone CSP reports and, where no stand-alone CSP report was published, sections of annual reports reporting on CSP were examined for the period between 2007 and 2010. Signalling was coded 1 if the company included the name or logo of the FTSE4Good Index in its reporting that year, and 0 otherwise. Although the logo is widely used in annual CSP communication, not all companies use the logo. Just over half (58\%) of the companies included in the Index used signalling in the observation period. Signalling is lagged by one year in the analysis to capture its effect on compliance and levels of CSP in subsequent years.

Third, we create the measure engagement based on the FTSE archive of correspondence with companies regarding the Countering Bribery criteria. As highlighted above, companies are not automatically excluded from the Index when they do not meet the criteria. Instead, they have the opportunity to enter into engagement with the FTSE RI team on the specific criteria they are not meeting. Only if a company is not responsive to the opportunity for discussion, or it is clear that it cannot or does not want to meet the criteria, will it be excluded at the initial deadline. Where a company is making progress and makes a formal written commitment to FTSE the FTSE4Good Policy Committee will normally approve an extension of the company's deadline. As the exclusion threat acts as a precursor to engagement, the variables are not independent and we analyse their effects in separate models. We include the measure of engagement to test the effects on a specific topic of 
CSP, in this case countering bribery. We collected the archived correspondence between the FTSE RI team and companies engaged on the Countering Bribery criteria (500+ emails), and summarised and coded their contents. To create an ordinal measure of engagement we coded for the length and intensity of the correspondence. The number of months the company is in engagement plus the number of company actions (e.g. sending more information, requesting a meeting etc.) are summed into a total score for engagement intensity. Engagement intensity is coded 'low' for the $1^{\text {st }}$ quartile; 'medium' for the $2^{\text {nd }}$ quartile, and 'high' for the $3^{\text {rd }}$ and $4^{\text {th }}$ quartile of the scores generated by coding the correspondence. A 'low' engagement score means the engagement lasted less than six months, which is the time between two Index reviews, and the company undertook relatively little action. More intensive engagement can be characterised by a flurry of company actions, engagement over a prolonged period of time, or both. Those classified in the high engagement category would have higher levels of company activity over a prolonged period of time. This ordinal measure of engagement corresponds to the idea that companies in intensive engagement are likely to benefit more from the dialogue between the FTSE RI team and corporate management. Again, engagement is lagged by one year to enable us to capture its effects on countering bribery practices in subsequent years.

\section{Control variables}

As Doh et al (2010) point out; the degree of information asymmetry regarding CSP can be reduced by intermediaries or by the firm itself. Transparency and good quality CSP reporting reduces information asymmetry and facilitates evaluation by intermediaries, as well as other stakeholders. Companies are more likely to provide information on relevant aspects of CSP if they have a history of being open about CSP practices and have set up corporate structures to report CSP and deal with information requests. We control for the quality of existing CSP 
reporting by extracting data from the Global Reporting Initiative (GRI) Sustainability Disclosure database. The GRI Sustainability Reporting Guidelines have become the de-facto standard for meaningful, high quality CSP reporting (Etzion \& Ferraro, 2010). First introduced in 1999, the current version of the Guidelines includes recommendations for disclosure on bribery and corruption. A company is coded 1 if it has reported to use the GRI and 0 otherwise, for each of the years in the observation period. If the company is using GRI, it is assumed that information asymmetry is lower, and that existing reporting systems may enable a faster response to new requests for CSP data from intermediaries.

We also control for firm characteristics that have been identified as introducing variance in CSP, such as organisational size, financial performance, risk, and industry sector (Orlitzky et al, 2003; Margolis, Elfenbein \& Walsh, 2007; Orlitzky \& Benjamin, 2001). Financial data were taken from Datastream. Organisational size was controlled for by taking the natural logarithm of the number of employees. An accountingbased measure of financial performance, return on assets, was used to control for financial performance, to reflect the company's use of resources and financial strength. The long-term debt to total assets ratio was taken as a proxy for financial risk (Waddock \& Graves, 1997). The industry sectors represented in the sample were restricted to those considered high risk for encountering bribery and corruption as per the FTSE classification (see appendix A). We expect that companies from high risk industry sectors will undertake more action to comply with CSP standards in this area, whilst we want to control for intra-industry differences. The number of industry sectors represented in the sample was coded following the Industry Classification Benchmark. The selected reference group, the technology sector, has above average scores in the Transparency International Bribe Payers index (meaning less reported instances of bribery) (Transparency International, 2011). Thus the industry sectors in the analysis were deemed higher risk for corruption and bribery relative to the reference group, technology. According to 
McWilliams and Siegel (2000; 2001, 2011), CSP can be viewed as a form of product innovation (i.e., the creation of new socially responsible product features or categories) or process innovation (i.e., the use of a socially responsible production process) (McWilliams \& Siegel 2011:1491). We thus control for R\&D expenditure by collecting data on intangible assets, including goodwill, patents, and copyright from Datastream. The natural logarithm of intangibles is used in the dataset. Lastly, the degree of government regulation may also influence how firms respond to activists' pressures (Chatterji \& Toffel, 2010; Reid \& Toffel, 2009). A dummy variable was created to control for companies based in the UK. Within Europe, the UK can be considered to have the most advanced regulation regarding corruption and bribery in the form of the UK Bribery Act (Osuji, 2011). Whilst the introduction of the UK Bribery Act was delayed and it only came into force in 2011, consultations regarding the act first started in 2002 and 2005. Therefore, companies in the UK might have anticipated the forthcoming regulation.

Analysis

Two models were estimated to test the hypotheses. The logit analysis in model 1 tests the effects of the exclusion threat and signalling on the general compliance with the FTSE4Good Index inclusion criteria; thus testing Hypotheses 1 and 2a. The Tobit analysis in model 2 tests the effects of signalling and engagement on the quality of Countering Bribery practices; testing Hypotheses $2 b$ and 3.The dependent variable in model 2 is censored in the sense that it can only have values between 0 and 9 , and cannot take negative values. This means a censored regression technique is necessitated since ordinary least squares (OLS) estimation can provide both biased and inconsistent parameter estimates (Greene 2008, Greene \& Hensher, 2010). The most commonly adopted solution to these types of data is to estimate a Tobit model using by maximum- 
likelihood estimation (e.g. see Brammer \& Millington, 2006; 2008). The Tobit model is suitable when the dependent variable is zero for a nontrivial proportion of the sample, and roughly continuously distributed over the positive values (Greene, 2008).

Both models are pooled to allow for the examination of variance over time. A pooled model effectively ignores individual effects to explore situations in which the main interest is in the effect of an intervention (in this case the introduction of the Countering Bribery criteria in the Index), the cases do not constitute a random sample of the population and the panel is unbalanced (Fiss \& Zajac, 2006; Hsiao, 1985: 1182-1183; Petersen, 1993). Time effects can be captured in pooled analysis by including year dummies. We have included dummy variables for the years in our observation period. All independent and control variables were lagged by one year in order to avoid reverse causality. This also makes sense substantially we expect the effects of engagement on CSP to develop over time. All variables were estimated with robust standard errors.

\section{Results}

The models were estimated using Stata 13. The descriptive statistics are provided in table 2. Table 3 provides the results of Model 1.

\section{Insert table 2 and 3 about here}

Model 1 illustrates the effects of exclusion threats and signalling on compliance with the FTSE4Good Index inclusion criteria. The coefficients in logit models are not straightforwardly interpreted as they are reported as the log of odds. To enable more intuitive interpretation, 
we present the results of the logit model in table 3 in odds ratios, which are interpreted in this model as the odds of compliance with FTSE4Good criteria/ odds of non-compliance with FTSE4Good Criteria. This allows a more intuitive interpretation of the results of the logit model. The results confirm Hypothesis 1, which predicted companies who are threatened by exclusion from RI indices are more likely to comply with the intermediary's general CSP criteria for index inclusion in subsequent years. Exclusion threat is positive and significant: the odds ratio shows that those companies that have encountered an exclusion threat in the previous year meeting FTSE4Good criteria is 2.875:1; i.e. companies that face exclusion threats are nearly 3 times more likely to meet the FTSE4Good criteria in subsequent years than those that don't. The results also confirm Hypothesis 2a, which predicted that companies that signal CSP reputation through intermediary endorsements are more likely to comply with the intermediary's CSP criteria in subsequent years. The results of the logit model shows the strength of the signalling effect, as the odds ratio for signalling can be interpreted as companies which signal inclusion in the FTSE4Good index in CSP disclosure are nearly 6 times more likely to meet the criteria the following year.

\section{Insert table 4 about here}

Table 4 reports the results of Model 2, the Tobit model that examines the effects of signalling and engagement regarding countering bribery issues on the quality of the Countering Bribery practices, as measured by the EIRIS scores. The results confirm the positive and significant effects of signalling, supporting Hypotheses $2 \mathrm{~b}$. Hypothesis 3, which predicted that those companies that take part in higher levels of 
engagement with the intermediary are more likely to have higher levels of CSP in subsequent years, is partially supported. We find that whilst the medium level of engagement is significant and positive, low and high levels of engagement are not significant. For the control variables, we find that the coefficients for CSP reporting, size, intangible assets, the oil \& gas, healthcare and utilities industries (in model 2 only), and the year dummies are all positive and significant $(\mathrm{p}<0.01)$.

\section{Discussion}

Previous research has taken a rather one dimensional view of intermediaries as information providers, which evaluate corporate practices against set standards, with improved information provision as the main outcome of this process. Within these studies, the improved information provision translates into signals regarding corporate reputation and legitimacy that may affect financial performance (King \& Whetten, 2008; Rindova et al, 2005; Doh et al, 2010). However these studies have not examined a number of additional roles that intermediaries may undertake. Our findings suggest RI intermediaries do more than providing legitimacy to companies when providing a benchmark for the evaluation of 'good' CSP. They may play an active role in fostering corporate sustainability. First, inclusion in RI indices such as the FTSE4Good Index creates a level playing field of legitimate companies with good CSP. By raising the bar for 'good CSP' through the introduction of new Index criteria, the FTSE4Good Index has incentivised companies to improve CSP. When FTSE introduces new Index inclusion criteria, this is taken as a signal that the relevant issue has become part of the CSP agenda and needs to be addressed accordingly. The results support the view that the FTSE RI team is able to successfully convince companies to comply with new Index inclusion criteria, by using the promise of continued index inclusion as a carrot and the threat of index deletion as a stick. 
Second, companies may also wish to leverage their perceived legitimacy in this field to signal CSP reputation, by differentiating their CSP disclosure from non-included companies by displaying the logos of RI indices. Whether focussing on overall compliance or performance on a specific issue such as countering bribery, we found that the effects of signalling are strong. The finding supports the idea that the FTSE4Good Index is used by companies as a certification of good CSP practices to strengthen reputation (Doh et al, 2010; Consolandi et al, 2009).

Third, RI intermediaries may undertake index engagement, which shows similar characteristics to shareholder engagement: a process of dialogue with company management regarding CSP performance that often requires significant investment in time and resources from both parties (Gond \& Piani, 2013; Gifford, 2010; Logsdon \& van Buren, 2009). Index engagement presses companies for more transparency on CSP, and also serves to provide companies information and guidance on index criteria. It may be used as new Index criteria such as the Countering Bribery criteria are introduced to large numbers of companies. Our findings show index engagement may be effective at encouraging companies to improve CSP. However, results were not consistent across all categories of engagement. The results show that whilst medium engagement produces higher CSP scores in subsequent years, lower and higher levels of engagement do not. This suggests that those companies that are either in short or protracted dialogues are less likely to ultimately improve their practices on specific CSP issues. It seems there is an optimum period of effective engagement (between 7 to 15 months in this case), after which the dialogue is less likely to lead improved CSP practices regarding bribery and corruption. This medium intensity engagement is most likely to produce results for intermediaries.

The findings further imply that using standardized templates for transparency and reporting on CSP facilitates evaluation by external rating agencies, and reduces information asymmetries with other stakeholders. Using the GRI reporting standards signals that reporting systems are in 
place to accommodate information requests from intermediaries. However, care should be taken in interpreting this finding, as the GRI provides only guidelines for reporting, not rigid standards. Companies which use the GRI may still display variance in their CSP disclosure to the public, including on issues related to countering bribery. With regards to the control variables, larger firms and those with greater intangible assets are more likely to have better Countering Bribery practices. The results show perhaps unsurprisingly that companies in industry sectors known for corruption scandals (e.g. Shell in Nigeria, or the unfolding case of GlaxoSmithKline in China) are more likely to have better anti-corruption systems. It was also found that companies in the UK, where there is stricter anti-corruption legislation in place, are more likely to have higher performance on countering bribery practices. This concurs with the findings by Chatterji and Toffel (2010) and Reid and Toffel (2009) who find that higher levels of government regulation leads to higher levels CSP. We also find time effects, showing that as more time has passed since the introduction of the Countering Bribery criteria in 2007, companies are more likely to be compliant and show higher levels of CSP on this issue.

\section{Implications and future research}

Our study has multiple implications for the study of corporate reputation and the role of intermediaries in signalling reputation in situations of information asymmetry, such as those related to CSP. First, standards for CSP do not appear out of nowhere, and intermediaries may play an active role in setting or promoting the norms, standards and behavioural guidelines that determine the legitimacy of corporate behaviour in a given field (Suchman 1995, Brunsson \& Jacobsson, 2000). As can be seen in the case of FTSE4Good, intermediaries may use the Index as both a carrot and stick to change corporate behaviour by continuously raising the bar for what is considered to be good CSP. In doing so, 
intermediaries must negotiate substantial cultural, legal and institutional differences in norms and standards for CSP around the world. Intermediaries' role in setting and diffusing globally accepted standards merits more critical attention in research on CSP and reputation.

Second, the research on corporate reputation rarely takes into account the feedback role of reputation intermediaries. Yet a growing stream of research on third party evaluation of organisational performance through rankings, ratings, certification and accreditation shows that the process of social evaluation incentivises changes in organisational behaviour, especially when reputational stakes are high (Sauder \& Espeland 2009; Elsbach \& Kramer, 1996). This feedback effect indicates the existence of multidirectional relationships between corporate practices, evaluation and reputation, that deserve further scrutiny.

Third, intermediaries may choose to play an active role through engagement with their subjects of evaluation. Engagement by intermediaries may range from the soliciting of information needed to evaluate performance to the active lobbying of management to comply with the criteria of evaluation. In the case of the FTSE4Good Index engagement was necessitated by the need to minimise turnover of Index constituents and the explicit objective for the Index to incentivise change in CSP (Slager et al, 2012). Whilst the FTSE4Good Index has been public about its engagement strategy, there may be examples of intermediaries where engagement is more obscured from public view. For example, certification or accreditation may only prove a valuable legitimating signal once a critical mass of participating organisations has been reached, and certification bodies may need to engage with their target organisation to convince them of the worth of certification (Durand \& McGuire, 2005). This engagement may be hidden from view, but, as our findings show, its effects on corporate practices need to be taken into account when studying the role of intermediaries. 
Finally, there is increasing recognition of the active role firms play in managing the reputational signals emitted by intermediaries. Elsbach and Kramer (1996) show that when rankings produced by intermediaries are perceived to be a threat to organisational identity , organisational members may choose to highlight other types of evaluation which align more closely with their values (Elsbach \& Kramer, 1996). With the multitude of rankings and lists that exist nowadays to measure CSP, it is easy for firms to promote only those that show them in good light. New research in institutional theory recognises organisational actors play an active role in establishing, maintaining or disrupting institutions (Lawrence \& Suddaby, 2006; Lawrence, Suddaby \& Leca, 2009), and this may include a more active response to market intermediaries that uphold institutions. For example, whereas securities analysts have traditionally been seen as a source of institutional pressure in financial markets (Zuckerman, 1999; Beunza \& Garud, 2007), current research have emphasised the active response of companies in offsetting or manipulating analysts' recommendations (Benner \& Ranganathan, 2012). Further research could examine whether and how CSP signals from intermediaries are managed by companies.

Our study also has implications for the study of engagement processes. Previous research on shareholder engagement has emphasised the unique and individual nature of interaction between shareholders and company management, indicating that each dialogue requires sufficient attention to be paid to specific company contexts as well as the CSP issue of concern. This finding may to some degree be an artefact of the research methods in these studies, which often employ a limited number of qualitative case studies with little comparative analysis (Gond \& Piani, 2013; Southwood, 2003; Gifford, 2010). Of course, due to the private nature of shareholder engagement dialogues, large datasets are hard to come by for researchers. Based on to the FTSE4Good dataset collated for this study, we show that index engagement can effectively involve 
large numbers of companies. Classifying companies into risk categories based on their exposure to CSP elements such as bribery and corruption means that a degree of inter-firm differences can still be taken into account, even when engaging large numbers of firms. The findings imply that index engagement may use the threat of exclusion as a stick and reputation signalling as a carrot to incentivise companies to comply with set CSP standards. Lastly, the findings indicate that there might be an optimal timeframe for engagement, and that protracted engagement might be less effective in achieving high levels of CSP, indicating other mechanisms such as exclusion should be considered at that point.

Our study has a number of limitations. The relatively short time span of the observation period (2007-2010) tells us little about longer term effects. Future work could analyse responses to index inclusion and engagement over longer periods of time. Furthermore, countering bribery practices form only one part of the spectrum of activities, processes and structures that make up CSP. Further work needs to be done before the findings might be generalised to other areas of CSP. For example, what is the role of regulation and voluntary initiatives in areas such as the protection of human rights or labour standards in the supply chain? The current analysis also isolates the companies identified as being at high risk for encountering bribery and corruption. Further research could identify whether the companies which face lower risk are more or less likely to respond to index inclusion and engagement and investigate the interactions between risk, reputation and engagement effects further. Lastly, our study looked at a specific type of intermediary only. Graffin \& Ward (2010) distinguish between different types of intermediaries, such as certification, rating and accreditation agencies and suggest each will have different effects on corporate reputation under situations of uncertainty. They suggest that these differences will depend on whether the outcome of evaluation is based on a relative rank ordering or a 
measure of absolute performance against the standard in question (Graffin \& Ward, 2010). Further research could explore different types of intermediaries, including those using absolute or relative performance benchmarks, to examine their effects.

\section{Conclusion}

Previous research shows that RI indices act as reputation intermediaries by evaluating information regarding CSP for investors and other stakeholders (Doh et al, 2010; Consolandi et al, 2009). Our research shows that the role of intermediaries is not confined to information provision. We identify three mechanisms that may influence CSP: exclusion threats, signalling and engagement. By explicating these mechanisms we provide a more comprehensive view of the role of intermediaries in conferring legitimacy and reputation for CSP. The identified mechanisms may be used to study the effects on CSP beyond the corruption and bribery context, as well as providing a useful framework to study the effects of other forms of engagement.

\section{Table 1. Variables used in the study}

\begin{tabular}{|c|c|c|c|c|}
\hline Dependent variable & Description & Data source & Coding/proxy & Testing \\
\hline Compliance & $\begin{array}{l}\text { Binary variable that indicates whether a } \\
\text { company meets the FTSE4Good Index } \\
\text { criteria }\end{array}$ & $\begin{array}{l}\text { FTSE4Good } \\
\text { database }\end{array}$ & $\begin{array}{l}1=\text { the company meets the Index criteria, } 0 \text { otherwise, for } \\
\text { period } 2007-2010\end{array}$ & $\begin{array}{l}\text { Model 1, } \\
\mathrm{H} 1, \mathrm{H} 2 \mathrm{a}\end{array}$ \\
\hline $\begin{array}{l}\text { Countering Bribery } \\
\text { practices }\end{array}$ & $\begin{array}{l}\text { Describes the total score given to } \\
\text { corporate countering bribery practices, } \\
\text { reflecting high levels of CSP in this area }\end{array}$ & EIRIS CSP data & $\begin{array}{l}\text { Summed score for quality of corporate policy, } \\
\text { management system, and reporting. Based on converted } \\
\text { numerical EIRIS scores, range between } 0 \text { (low) and } 9 \\
\text { (high), for period 2007-2010 }\end{array}$ & $\begin{array}{l}\text { Model 2, } \\
\mathrm{H} 2 \mathrm{~b}, \mathrm{H} 3\end{array}$ \\
\hline
\end{tabular}




\begin{tabular}{|c|c|c|c|c|}
\hline \multicolumn{5}{|c|}{ Independent variables } \\
\hline Exclusion threat & $\begin{array}{l}\text { The company is threatened with } \\
\text { exclusion for not meeting the } \\
\text { FTSE4Good Countering Bribery criteria }\end{array}$ & $\begin{array}{l}\text { FTSE4Good } \\
\text { database }\end{array}$ & $\begin{array}{l}1=\text { the company is included in the Index, but does not } \\
\text { meet the Countering Bribery practices, } 0 \text { otherwise, for } \\
\text { period } 2007-2010\end{array}$ & H1 \\
\hline Signalling & $\begin{array}{l}\text { The company communicates its inclusion } \\
\text { in the FTSE4Good Index to stakeholders }\end{array}$ & $\begin{array}{l}\text { Corporate CSP } \\
\text { reporting }\end{array}$ & $\begin{array}{l}1=\text { the company uses the name/logo of the Index in its } \\
\text { communications, } 0 \text { otherwise, for period } 2007-2010\end{array}$ & $\mathrm{H} 2 \mathrm{a}, \mathrm{b}$ \\
\hline Engagement & $\begin{array}{l}\text { The intensity of the engagement process } \\
\text { with the FTSE RI team }\end{array}$ & $\begin{array}{l}\text { FTSE } \\
\text { correspondence }\end{array}$ & $\begin{array}{l}\text { Number of months the dialogue lasted plus number of } \\
\text { company actions undertaken during dialogue; } 1^{\text {st }} \text { quartile } \\
\text { coded 'low', } 2^{\text {nd }} \text { quartile coded 'medium', } 3^{\text {rd }} \text { and } 4^{\text {th }} \\
\text { quartile 'high' }\end{array}$ & $\mathrm{H} 3$ \\
\hline \multicolumn{5}{|l|}{ Control variables } \\
\hline CSP reporting & $\begin{array}{l}\text { The company uses the GRI to report on } \\
\text { CSP }\end{array}$ & GRI Database & $\begin{array}{l}1=\text { the company uses GRI, } 0 \text { otherwise, for the period } \\
2007-2010\end{array}$ & \\
\hline Size & The size of the company & Datastream & Natural logarithm of number of employees & \\
\hline ROA & Financial performance of the company. & Datastream & Return on Assets & \\
\hline Risk & Management risk tolerance & Datastream & Long-term Debt/Total Assets & \\
\hline Intangibles & $\begin{array}{l}\text { Intangible assets including goodwill, } \\
\text { patents, and copyright }\end{array}$ & Datastream & Natural logarithm of intangible assets & \\
\hline Industry & ICB classification (supersector) & FTSE/EIRIS & $\begin{array}{l}\text { Including Oil \& Gas, Basic Materials, Industrials, } \\
\text { Consumer Goods, Healthcare, Telecom, Utilities }\end{array}$ & \\
\hline UK & $\begin{array}{l}\text { Dummy variable indicating a company is } \\
\text { listed in the UK }\end{array}$ & FTSE/EIRIS & $1=$ listed in the UK, 0 otherwise & \\
\hline
\end{tabular}


Table 2. Summary statistics and correlations

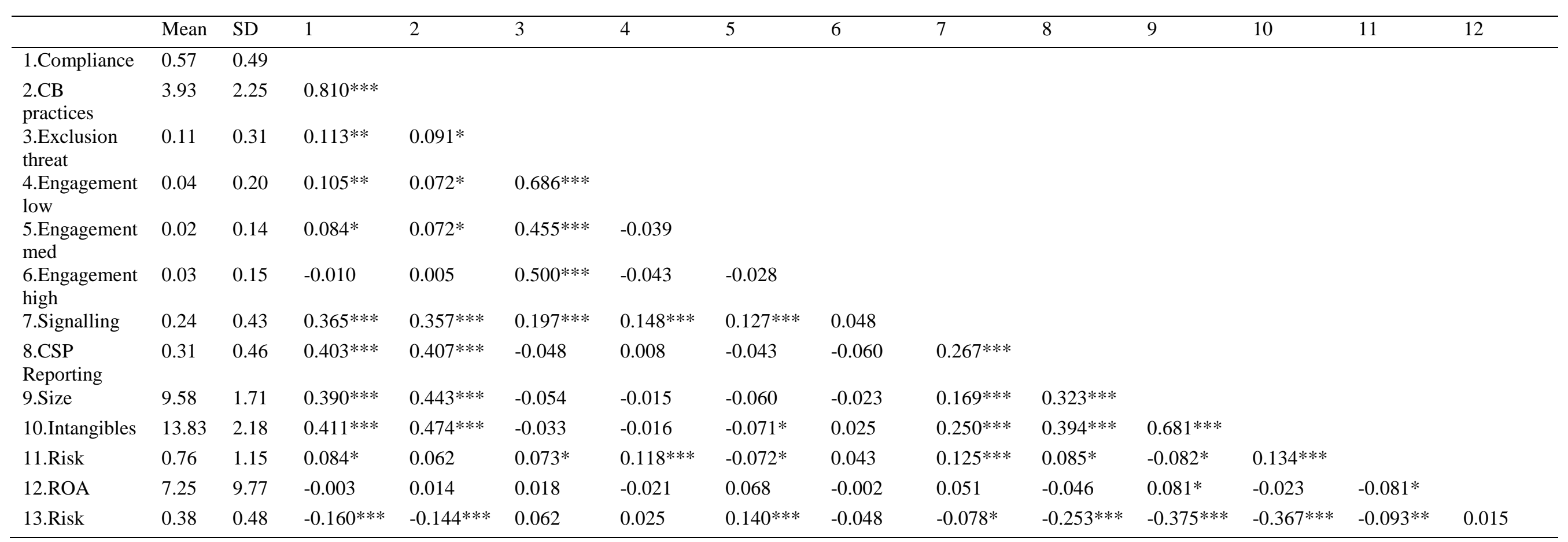

$* \mathrm{p}<0.05 * * \mathrm{p}<0.01 * * * \mathrm{p}<0.001$ 
Table 3.Binary logit analysis of compliance with the FTSE4Good criteria

\begin{tabular}{ll}
\hline & Model 1 \\
\hline Exclusion threat & $2.875^{* *}$ \\
Signalling & $5.702^{* * *}$ \\
CSP reporting & $3.410^{* * *}$ \\
Size & $1.608^{* * *}$ \\
Intangibles & $1.176^{* *}$ \\
Risk & 1.139 \\
ROA & 0.983 \\
Oil \& Gas & $2.801^{* *}$ \\
Basic Materials & 1.127 \\
Industrials & 1.349 \\
Consumer goods & 1.023 \\
Healthcare & $8.715^{* * *}$ \\
Telecommunications & 0.402 \\
Utilities & 1.253 \\
UK & 1.386 \\
2008 & $2.082^{* *}$ \\
2009 & $3.354^{* * *}$ \\
2010 & $3.426 * * *$ \\
& \\
N & 813 \\
pseudo R & \\
Wald chi & \\
df & 0.313 \\
Log pseudo likelihood & -387.18 \\
\hline Odds ratios reported, * $\mathrm{p}^{2}<0.05 * * \mathrm{p}<0.01 * * * \mathrm{p}<0.001$ \\
\end{tabular}


Table 4. Tobit analysis of the quality of Countering Bribery practices

Model 2

\begin{tabular}{lll}
\hline Signalling & $1.231 * * *$ & $1.268 * * *$ \\
Engagement low & 0.513 & \\
Engagement med & $1.241 * * *$ & $1.185 * * *$ \\
Engagement high & & 0.381 \\
CSP reporting & $0.872 * * *$ & $0.884 * * *$ \\
Size & $0.458 * * *$ & $0.464 * * *$ \\
Intangibles & $0.204 * * *$ & $0.199 * * *$ \\
Risk & 0.0419 & 0.0545 \\
ROA & 0.00238 & 0.00194 \\
Oil \& Gas & $1.217 * * *$ & $1.172 * * *$ \\
Basic Materials & 0.0669 & 0.0271 \\
Industrials & $0.608 *$ & $0.564 *$ \\
Consumer goods & -0.276 & -0.305 \\
Healthcare & $1.582 * * *$ & $1.530 * * *$ \\
Telecommunications & -0.282 & -0.375 \\
Utilities & $0.982 * *$ & $0.963 * *$ \\
UK & $0.528 * *$ & $0.549 * * *$ \\
2008 & $1.165 * * *$ & $1.208 * * *$ \\
2009 & $1.595 * * *$ & $1.609 * * *$ \\
2010 & $1.670 * * *$ & $1.663 * * *$ \\
& & \\
N & 798 & 798 \\
pseudo R & & \\
F & 0.134 & 0.133 \\
Log pseudo likelihood & $37.94 * * *$ & $37.96 * * *$ \\
\hline & -1532.07 & -1533.03 \\
\hline
\end{tabular}

$* \mathrm{p}<0.05, * * \mathrm{p}<0.01, * * * \mathrm{p}<0.00$ 


\section{Appendix A. FTSE4Good Countering Bribery Criteria}

\begin{tabular}{|c|c|c|c|}
\hline \multicolumn{2}{|r|}{ Risk Classification* } & \multicolumn{2}{|r|}{ FTSE4Good Countering Bribery Criteria Indicators } \\
\hline Sector & $\begin{array}{l}\text { Companies from the following ICB (Industry Classification } \\
\text { Benchmark) sectors and sub-sectors are considered more likely to } \\
\text { have the highest levels of exposure to risk of engaging in bribery: } \\
\text { - Oil \& Gas Producers; Oil Equipment, Services, \& } \\
\text { Distribution; Chemicals; Industrial Metals; Mining; } \\
\text { Construction \& Materials; Aerospace \& Defense; General } \\
\text { Industrials; Electronic \& Electrical Equipment; Industrial } \\
\text { Engineering; Support Services; Electricity; Gas, Water, \& } \\
\text { Multi-Utilities. } \\
\text { Pharmaceuticals; Hotels; Fixed Line Telecommunications; } \\
\text { Mobile Telecommunications; Software \& Computer Services; } \\
\text { Technology Hardware \& Equipment }\end{array}$ & Policy & 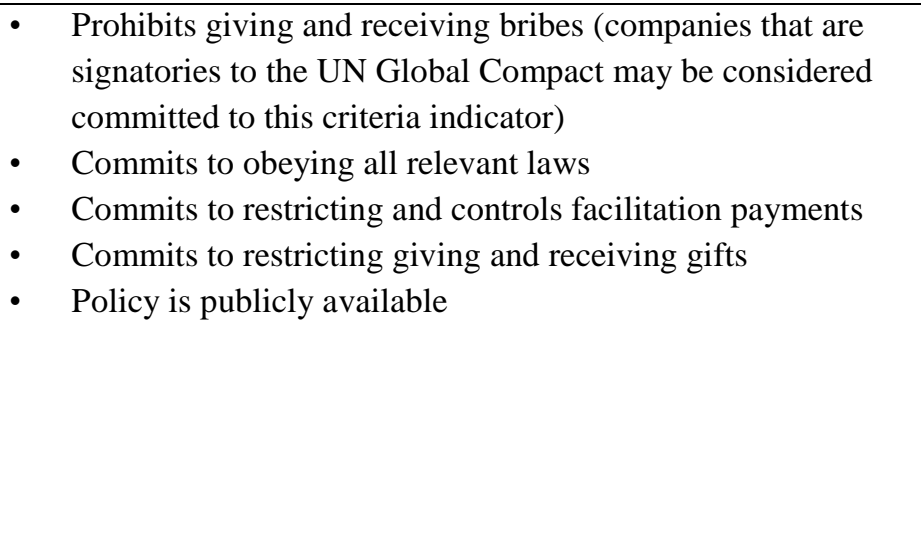 \\
\hline Countries & $\begin{array}{l}\text { Companies operating in countries that are deemed to have the } \\
\text { highest risk, or perceived risk of, levels of bribery: } \\
\text { - Countries scoring } 4 \text { or less on the Transparency International } \\
\text { Corruption Perceptions Index. } \\
\text { - Countries scoring } 0 \text { or less (negative) on the World Bank } \\
\text { Governance Indicators list. }\end{array}$ & Management & $\begin{array}{ll}\text { - } & \text { Communicates policy to employees } \\
\text { - } & \text { Trains relevant employees } \\
\text { - } & \text { Compliance mechanisms (e.g. assurance, audits, monitoring, } \\
\text { board reports) } \\
\text { - }\end{array}$ \\
\hline $\begin{array}{l}\text { Public } \\
\text { contracts }\end{array}$ & $\begin{array}{l}\text { Companies that are involved in any way with } \\
\text { government/public contracts, or where a government licence is } \\
\text { critical to the operation of their business, are considered as } \\
\text { having the highest levels of exposure to risk of engaging in } \\
\text { bribery. }\end{array}$ & Reporting & $\begin{array}{ll}\text { - } & \text { Policy is publicly disclosed } \\
\text { - } & \text { Compliance mechanisms are publicly disclosed }\end{array}$ \\
\hline
\end{tabular}

*All three filters must apply to each company before they are designated 'High Risk'

**Where there is a significant and credible controversy/allegation that a company, its business partners, including suppliers, contractors or agents are committing bribery, the

company must have taken visible, demonstrable or quantifiable steps to prove it has investigated these allegations effectively and in a timely manner 


\section{References}

Benner, M. J. \& R. A. M. Ranganathan (2012). Offsetting illegitimacy? How pressures from securities analysts influence incumbents in the face of new technologies. Academy of Management Journal, 55, 213-233.

Beunza, G. \& R. Garud (2007). Calculators, lemmings or frame-makers? The intermediary role of security analysts. In Market devices, eds. M. Callon, Y. Millo \& F. Muniesa, 13-39. Malden: Blackwell Publishing.

Bertels, S. \& J. Peloza (2008). Running Just to Stand Still? Managing CSR Reputation in an Era of Ratcheting Expectations. Corporate Reputation Review, 11(1), 56-72.

Brammer, S. \& A. Milllington (2006). Firm size, organizational visibility and corporate philanthropy: an empirical analysis Business Ethics: A European Review, $15,6-18$.

Brammer, S. \& A. Millington (2008). Does it pay to be different? An analysis of the relationship between corporate social and financial performance Strategic Management Journal, 29, 1325-1343.

Brunsson, N. \& B. Jacobsson (2000). A world of standards. Oxford: Oxford University Press. Capelle-Blancard, G. \& N. Couderc (2009) The Impact of Socially Responsible Investing: Evidence from Stock Index Redefinitions. Journal of Investing, 18, 76-86.

Chatterji, A. \& M. W. Toffel (2010) How firms respond to being rated. Strategic Management Journal, 31, (9), 917-945.

Clark, G. L. \& T. Hebb (2004) Pension Fund Corporate Engagement: The Fifth Stage of Capitalism. Relations Industrielles, 59, 142.

Collison, D. J., G. Cobb, D. M. Power \& L. A. Stevenson (2008) The financial performance of the FTSE4Good Indices. Corporate Social Responsibility and Environmental Management, 15, 14-28.

Consolandi, C., A. Jaiswal-Dale, E. Poggiani \& A. Vercelli (2009) Global Standards and Ethical Stock Indexes: The Case of the Dow Jones Sustainability Stoxx Index. Journal of Business Ethics, 87, 185-197.

Curran, M. M. \& D. Moran (2007) Impact of the FTSE4Good Index on firm price: An event study. Journal of Environmental Management, 82, 529-537.

Deephouse, D. L. \& S. M. Carter (2005) An Examination of Differences Between Organizational Legitimacy and Organizational Reputation. Journal of Management Studies, 42, 329-360.

Deephouse, D.L. \& M. Suchman (2008) Legitimacy in Organization Institutionalism. In: Greenwood, R., Oliver, C.,Suddaby, R., Sahlin-Andersson, K. (Eds.)The Handbook of Organizational Institutionalism. Thousand Oaks, CA: SAGE Publications.

Doh, J. P., S. D. Howton, S. W. Howton \& D. S. Siegel (2010) Does the Market Respond to an Endorsement of Social Responsibility? The Role of Institutions, Information, and Legitim. Journal of Management, 36, 1461-1485.

Durand, R. \& J. McGuire (2005) Legitimating Agencies in the Face of Selection: The Case of AACSB. Organization Studies, 26, 165-196.

Elsbach, K. D. \& R. M. Kramer (1996) Members' responses to organizational identity threats: Encountering and countering the Business Week rankings. Administrative Science Quarterly, 41, 442-746.

Espeland, W. N. \& M. Sauder (2007) Rankings and reactivity: how public measures recreate social worlds. American Journal of Sociology, 113, 1-40.

Etzion, D. \& F. Ferraro (2010) The role of analogy in the Institutionalization of Sustainability Reporting. Organization Science, 21, 1092-1107. 
Fiss, P. C. \& E. J. Zajac (2006) The Symbolic Management Of Strategic Change:

Sensegiving Via Framing And Decoupling. Academy of Management Journal, 49, 1173-1193.

Fombrun, C. \& M. Shanley (1990) What's in a Name? Reputation Building and Corporate Strategy. Academy of Management Journal, 33, 233-258.

FTSE (2010). FTSE4Good Index Series Inclusion Criteria.

FTSE (2011) FTSE4Good 10 years of impact \& investment. All on: http://www.ftse.com/Indices/FTSE4Good_Index_Series/F4G_Download_Page.jsp

Gifford, E. (2010) Effective Shareholder Engagement: The Factors that Contribute to Shareholder Salience. Journal of Business Ethics, 92, 79-97.

Gond, J.-P. \& V. Piani (2013) Enabling Institutional Investors' Collective Action: The Role of the Principles for Responsible Investment initiative. Business \& Society, 52, 64104.

Graffin, S. D. \& A. J. Ward (2010) Certifications and Reputation: Determining the Standard of Desirability Amidst Uncertainty. Organization Science, 21, 331-346.

Greene, W. H. (2008). Econometric Analysis. Upper Sadle River, NJ: Pearson.

Greene, W. H. \& D. A. Hensher. (2010). Modeling ordered choices. A primer. Cambridge: Cambridge University Press.

Griffin, J. J. \& J. F. Mahon (1997) The corporate social performance and corporate financila performance debate. Twenty-five year of incomparable research. Business \& Society, 36, 5-31.

Hsiao, C. 1985. Analysis of panel data. Cambridge: Cambridge University Press.

King, B. G. \& D. A. Whetten (2008) Rethinking the Relationship Between Reputation and Legitimacy: A Social Actor Conceptualization. Corporate Reputation Review, 11, 192-207.

Lawrence, T. B. \& R. Suddaby. (2006). Institutions and Institutional Work. In The SAGE Handbook of Organization studies, eds. S. R. Clegg, T. B. Lawrence \& W. R. Nord, 215-254. London: SAGE publications.

Lawrence, T. B., R. Suddaby \& B. Leca. (2009) Institutional Work. Actors and Agency on Institutional Studies of Organizations. Cambridge: Cambridge University Press.

Logsdon, J. \& H. Buren (2009) Beyond the Proxy Vote: Dialogues Between Shareholder Activists and Corporations. Journal of Business Ethics, 87, 353-365..

Love, E. G. \& M. Kraatz (2009) Character, conformity, or the bottom line? How and why downsizing affected corporate reputation. Academy of Management Journal, 52, 314335.

Mackenzie, C., Rees, W., \& Rodionova, T. 2013. Do Responsible Investment indices improve corporate social responsibility? FTSE4GOOD's impact on environmental management. Corporate Governance: An International Review, 21(5): 495-512.

Margolis, J. D., H. A. Elfenbein \& J. P. Walsh.(2007). Does it pay to be good? A metaanalysis and redirection of research on the relationship between corporate social and financial performance. Unpublished manuscript.

McLaren, D. (2004) Global Stakeholders: corporate accountability and investor engagement. Corporate Governance: An International Review, 12, 191-201.

McWilliams, A. \& D. Siegel (2000) Corporate social responsibility and financial performance: correlation or misspecification? Strategic Management Journal, 21, 603-609.

--- (2001) Corporate Social Responsibility: A Theory Of The Firm Perspective. Academy of Management Review, 26, 117-127. 
--- (2011) Creating and Capturing Value. Strategic Corporate Social Responsibility, Resource-Based Theory, and Sustainable Competitive Advantage. Journal of Management, 37, 1480-1495.

Orlitzky, M., J.D. Benjamin (2001) Corporate social performance and firm risk: A metaanalytic review. Business \& Society, 40, 369-396.

Orlitzky, M., F. L. Schmidt \& S. L. Rynes (2003) Corporate social and financial performance: A meta-analysis. Organization Studies, 24, 403.

Osuji, O. (2011) Fluidity of Regulation-CSR Nexus: The Multinational Corporate Corruption Example. Journal of Business Ethics, 103, 31-57.

Oulton, W. (2006). The role of activism in responsible investment: the FTSE4Good indices. In R. Sullivan \& C. Mackenzie (Eds.) Responsible Investment, . Sheffield: Greenleaf Publishing.

Petersen, T. (1993). Recent advances in longitudinal methodology. In J. Blake \& J. Hagan (Eds.) Annual review of sociology, , 425-454. Palo Alto, CA: Annual Reviews.

Quin Trank, C. \& M. Washington. (2009). Maintaining an institution an a contested organizational field: the work of the AACSB and its constituents. In T. B. Lawrence, R. Suddaby \& B. Leca (Eds) Institutional work. Actors and agency in institutional organizations, . Cambridge: Cambridge University Press.

Rao, H. (1994) The social construction of reputation: certification contests, legitimation and the survival of organizations in the American automobile industry: 1895-1912. Strategic Management Journal, 15, 29-44.

--- (1998) Caveat emptor: the construction of nonprofit consumer watchdog organizations. The American Journal of Sociology, 103, 912-961.

Reid, E. M. \& M. W. Toffel (2009) Responding To Public And Private Politics: Corporate Disclosure Of Climate Change Strategies. Strategic Management Journal, 30, 11571178.

Rhee, M. \& M. E. Valdez (2009) Contextual Factors Surrounding Reputation Damage With Potential Implications For Reputation Repair. Academy of Management Review, 34, 146-168.

Rindova, V. P., I. O. Williamson, A. P. Petkova \& J. M. Sever (2005) Being Good Or Being Known: An Empirical Examination Of The Dimensions, Antecedents, And Consequences Of Organizational Reputation. Academy of Management Journal, 48, 1033-1049.

RobecoSAM (2013) The Sustainability Yearbook 2013. www.robecosam.com

Robinson, M., A. Kleffner \& S. Bertels (2011) Signaling Sustainability Leadership: Empirical Evidence of the Value of DJSI Membership. Journal of Business Ethics, 101, 493-505.

Sauder, M. (2006) Third Parties and Status Position: How the Characteristics of Status Systems Matter. Theory and Society, 35, 299-321.

--- (2008) Interlopers and field change: the entry of U.S. News into the field of legal education. Administrative Science Quarterly, 53, 209-234.

Sauder, M. \& W. N. Espeland (2009) The discipline of rankings: Tight coupling and organizational change. American Sociological Review, 74, 62-82.

Scalet, S. \& T. F. Kelly (2009) CSR Rating Agencies: What is their global impact. Journal of Business Ethics, 94, 69-88.

Scott, R. W. 2001. Institutions and organizations. Thousand Oaks: Sage Publications.

Slager, R., J.-P. Gond \& J. Moon (2012) Standardization as Institutional Work: The Regulatory Power of a Responsible Investment Standard. Organization Studies, 33, 763-790. 
Southwood, P. (2003) Shareholder engagement: prospects for improving corporate social responsibility. International Journal Business Performance Management, 5, 223-236.

Suchman, M. C. (1995) Managing legitimacy: Strategic and institutional approaches. Academy of Management. The Academy of Management Review, 20, 571-610.

Sullivan, R. \& C. Mackenzie (2008) Can Investor Activism Play a Meaningful Role in Addressing Market Failures? The Journal of Corporate Citizenship, 77-88.

Transparency International Bribe Payers Index (2011). http://bpi.transparency.org/bpi2011/

Vandekerckhove, W., J. Leys \& D. Van Braeckel (2007) That's not what happened and it's not my fault anyway! An exploration of management attitudes towards SRIshareholder engagement. Business Ethics: A European Review, 16, 403-418.

Waddock, S. A. \& S. B. Graves (1997) The Corporate Social Performancefinancial Performance Link. Strategic Management Journal, 18, 303-319.

Wai Kong Cheung, A. (2011) Do Stock Investors Value Corporate Sustainability? Evidence from an Event Study. Journal of Business Ethics, 99, 145-165.

Zuckerman, E. W. (1999) The Categorical Imperative: Securities Analysts and the Illegitimacy Discount. The American Journal of Sociology, 104, 1398-1438.

--- (2000) Focusing the Corporate Product: Securities Analysts and De-diversification. Administrative Science Quarterly, 45, 591-619. 